Classification

Physics Abstracts

$61.50 \mathrm{C}-07.80-61.70$

\title{
Observation of Melt Growth Process of Bi and Sn Thin Films
}

\author{
Shigeo Sugawara and Jirô Watanabé \\ Department of Materials Engineering and Applied Chemistry, Mining College, Akita University, \\ Tegata, Akita 010, Japan
}

(Received January 11, 1993; accepted February 26, 1993)

\begin{abstract}
We observed melt-growth process of Bi and $\mathrm{Sn}$ thin films by in-situ transmission electron microscopy. After preparing the films with some specified orientations from bulk single crystals of $\mathrm{Bi}$ (99.9 and $99.9999 \%)$ and Sn $(99.999 \%)$, we partially melted and regrew them by cooling at a nearly constant rate in an electron microscope. In the Bi films, a growing solid-liquid interface was observed to be concave toward melt more frequently than faceted. The movement of the curved interface was sensitive to small fluctuations of the falling temperature, while the faceted interface was insensitive. During the melt growth various crystal defects were introduced, and their density depends on the orientation, purity of films and the cooling condition. In the Sn films, a growing interface was always curved. The defects formed were confined to lineage defects, of which formation was not influenced by the cooling rate but by the film orientation.
\end{abstract}

\section{Introduction.}

In-situ observation of melting and solidification processes of metallic films has been made by the use of a transmission electron microscope (TEM) in order to study grain boundary melting [1-4], microscopic morphology of a solid-liquid interface [5-9], melting transition [10,11], nucleation behavior of melting or solidification [6,12-16] and behavior of dislocations in melting [17]. However, it can be pointed out that information on behavior of melt growth is lacking, while the melt growth has been observed by X-ray topography on crystals of Sn[18] and Al[19-22]. Recently our research group successfully observed behavior of a growing interface and a crystal defect during the melt growth of Bi (11) films [23] of purity 3N's and (100) films [24] of purity 3N's and 6N's in a TEM by adopting a heating system to enable the film specimen to be cooled at a nearly constant rate. From a comparison of the phenomena observed in both films they suggested the effect of film orientation [24] on morphology of a solid-liquid interface and formation of a crystal defect.

As an extension of those studies, we have observed melt growth of $\mathrm{Bi}$ (111) films of purity $3 \mathrm{~N}$ 's and $6 \mathrm{~N}$ 's by transmission electron microscopy in order to get further information concerning the effects of orientation and purity of the films on the melt growth. Moreover, we have been interested in melt growth of (100) and (001) films of $\beta$-Sn which displays more important metallic behavior than $\mathrm{Bi}$. In this paper, we present some major results of in-situ observations of the melt growth of $\mathrm{Bi}$ and $\mathrm{Sn}$ films. Further details will be reported elsewhere. 


\section{Experimental procedures.}

Single crystals of Bi (nominal purity 3N's and 6N's) and Sn (nominal purity 5N's) were grown in a purified Ar atmosphere by the Czochralski method and their orientations were determined by the light figure method [25]. After cutting along a (111) $\left(^{\star}\right)$ plane of Bi crystals and along (100) and (001) planes of $\beta$-Sn crystals by a spark cutter, slices obtained were thinned by chemical polishing and cut into polygonal discs of about $3 \mathrm{~mm}$ in width. Film specimens for examination in a TEM were obtained by a jet polishing and a final electropolishing: the latter polishing was carried out in concentrated hydrochloric acid + methanol + butyl cellosolve (5:19:1 in volume ratio, 269$278 \mathrm{~K}$ ) at an applied voltage of 7-13 V for $\mathrm{Bi}$ and in perchloric acid + methanol + butyl cellosolve $(3: 15: 2$ in volume ratio, $273-283 \mathrm{~K})$ at $15 \mathrm{~V}$ for $\mathrm{Sn}$. Mean thickness of observable regions near a perforation of the specimens was about $0.1 \mu \mathrm{m}$. Finally, carbon was deposited on both faces of the film in order to prevent vaporization of the molten film and its cohesion followed by de-wetting in a TEM.

The thin film thus prepared was fixed on a specimen holder and it was mounted on a heating stage in a TEM (JEOL, JEM-200A). In order to control the specimen temperature, two types of controllers were employed. For one type, direct current was supplied to a heater of the holder through a servo-resistor which was regulated by a PID controller of on-and-off type, and a programmer enabled the temperature to follow a given pattern. This system is the same as that employed in the previous experiments [23,24], and we will call this system the old-type or A-type controller. When the temperature was lowered at a slow rate of $8.3 \times 10^{-3} \mathrm{~K} / \mathrm{s}$, a cooling curve exhibited a small temperature oscillation; its amplitude ranged from 0.01 to $0.06 \mathrm{~K}$ and its periodicity varied from 2.1 to $2.3 \mathrm{~s}$. For the other controller, alternating current was regulated by a combination of an SCR and a PID controller of current-input type; rectified current was supplied to the heater. We will call this system the new-type or B-type controller. The temperature-time curve at a programmed rate of $8.3 \times 10^{-3} \mathrm{~K} / \mathrm{s}$ was very smooth with this type of controller.

In-situ observation of the melt growth was carried out under an accelerating voltage of $200 \mathrm{kV}$. When a molten part spread just over a view field, the temperature was lowered at a rate of $8.3 \times 10^{-3}$ to $2.7 \times 10^{-1} \mathrm{~K} / \mathrm{s}$, as indicated in Table I. Tested number of Bi specimens was twentyone to thirty-seven, while number of Sn specimens was forced to be less, particularly in the (001) films, which was caused by the de-wetting facility of molten $\mathrm{Sn}$. The morphology of growing interface and the formation of crystal defects were observed. The dynamic behavior of interfaces was recorded on a video-tape using a TV imaging system in order to determine its velocity.

\section{Experimental Results and Discussion.}

3.1 GROWING INTERFACE IN Bi FILMS. - During the melt growth of Bi (111) films, two types of solid-liquid interfaces appeared. Typical morphology is shown in figure 1. Dark areas correspond to liquid and light areas represent solid, where selected area diffraction patterns could be used to distinguish the solid from the melt. The curved interface in figure 1a is concave toward the melt, corresponding to an isotherm. On the other hand, faceted interfaces in figure $1 \mathrm{~b}$ are joined by a small curved surface, and each facet trace lay in a $\langle 1 \overline{1} 0\rangle$ direction. It is inferred that the facets would correspond to low-index planes.

When the A-type controller was used to lower the temperature at a slow rate of $8.3 \times 10^{-3} \mathrm{~K} / \mathrm{s}$, the curved interface predominantly appeared and advanced back-and-forth in response to the external temperature oscillation. Under the same cooling condition, the faceted interface sometimes appeared and for that case advanced stepwise or steadily without back-melting. The curved

$\left({ }^{\star}\right)$ We use Miller's indexes in a face-centered rhombohedral notation for a lattice plane of Bi. 
Table I. - Cooling conditions for the melt growth of Bi and Sn film specimens in a transmission electron microscope.

\begin{tabular}{|c|c|c|c|c|c|}
\hline \multicolumn{3}{|c|}{ Film } & \multicolumn{2}{|c|}{ Cooling } & \multirow{2}{*}{$\begin{array}{l}\text { Number of } \\
\text { tested } \\
\text { specimens }\end{array}$} \\
\hline Material & Orientation & Purity & Controller & Rate $(\mathrm{K} / \mathrm{s})$ & \\
\hline \multirow{7}{*}{$\mathrm{Bi}$} & \multirow{7}{*}{ (111) } & $3 N$ 's & \multirow{2}{*}{$\begin{array}{l}\text { old-type } \\
\text { (A-type) }\end{array}$} & \multirow{2}{*}{$8.3 \times 10^{-3}$} & 37 \\
\hline & & $6 N^{\prime} \mathrm{s}$ & & & 30 \\
\hline & & $3 N$ 's & \multirow{5}{*}{$\begin{array}{l}\text { new-type } \\
\text { (B-type) }\end{array}$} & \multirow{2}{*}{$8.3 \times 10^{-3}$} & 21 \\
\hline & & \multirow{4}{*}{$6 N^{\prime} s$} & & & 30 \\
\hline & & & & $1.7 \times 10^{-2}$ & 22 \\
\hline & & & & $6.7 \times 10^{-2}$ & 21 \\
\hline & & & & $2.7 \times 10^{-1}$ & 31 \\
\hline \multirow{8}{*}{$\mathrm{Sn}$} & \multirow{4}{*}{$(100)$} & \multirow{8}{*}{$5 \mathrm{~N}$ 's } & \multirow{8}{*}{$\begin{array}{l}\text { new-type } \\
\text { (B-type) }\end{array}$} & $8.3 \times 10^{-3}$ & 10 \\
\hline & & & & $1.7 \times 10^{-2}$ & 11 \\
\hline & & & & $6.7 \times 10^{-2}$ & 12 \\
\hline & & & & $2.7 \times 10^{-1}$ & 15 \\
\hline & \multirow{4}{*}{$(001)$} & & & $8.3 \times 10^{-3}$ & 1 \\
\hline & & & & $1.7 \times 10^{-2}$ & 1 \\
\hline & & & & $6.7 \times 10^{-2}$ & 6 \\
\hline & & & & $2.7 \times 10^{-1}$ & 10 \\
\hline
\end{tabular}

interface showed a stepwise advancement at an intermediate cooling rate of $1.7 \times 10^{-2}$ or $6.7 \times$ $10^{-2} \mathrm{~K} / \mathrm{s}$, and a steady advancement at a high cooling rate of $2.7 \times 10^{-1} \mathrm{~K} / \mathrm{s}$. When a film was grown without the temperature oscillation by utilizing the new-type controller, both the curved interface and the faceted one showed the steady advancement at any cooling rates.

The curved interface developed more frequently at higher cooling rates in the $6 \mathrm{~N}$ 's films. In the $3 \mathrm{~N}$ 's films grown in the presence of a small temperature oscillation, the faceting was more remarkable than in the films grown in the absence of the oscillation, though the faceted interface developed equally in the high purity films grown under both cooling conditions. On the other hand, the growing interface was sometimes faceted in the (100) film [24] when it was always concave in the $(11 \overline{1})$ films [23]. These results indicate that the micromorphology of growing interface depended markedly on the crystal orientations.

The morphology of growing interface can be predicted from the Jackson's parameter $\alpha$ [26]. If $\alpha>2$ the interface would be smooth atomically and hence it would display a facet. If $\alpha<2$ the interface would be atomically rough. However, Jackson's criterion is not strictly valid for semimetallic materials with $2<\alpha<3[26,27]$. As the value of $\alpha$ for $\mathrm{Bi}$ is 2.39 , it is inferred that faceting does not always occur according to the film orientation and the cooling rate. 


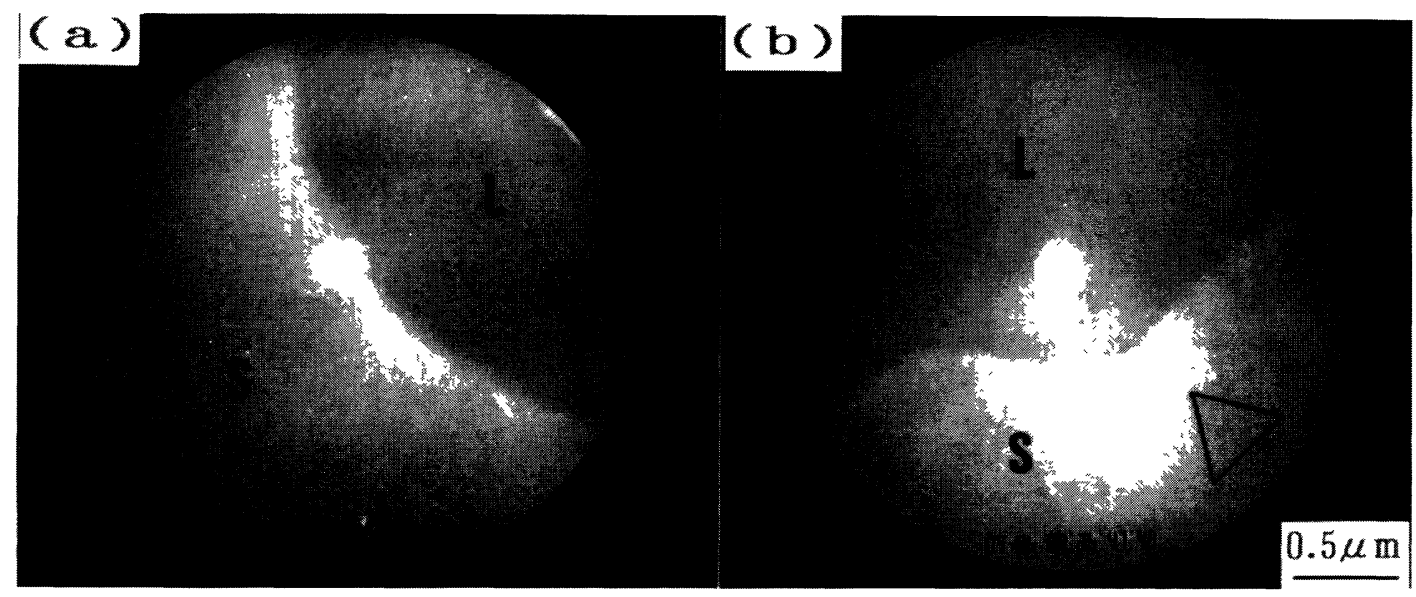

Fig. 1. - Video-recorded images showing the morphology of a growing interface of (111) films of Bi (purity 6 N's). a) Curved interface and b) faceted interface. The sides of a triangle inserted in (b) correspond to $\langle 1 \overline{1} 0\rangle$ directions.

With an increase of the cooling rate of $6 \mathrm{~N}$ 's films by using the new-type controller, the velocity of curved and faceted interface increased linearly. However, the velocity of faceted interface was slightly smaller than that of curved interface at any cooling rates. According to the kinetic theory of melt growth [28], the velocity of curved interface is controlled by the continuous growth mechanism, and the velocity of faceted interface is controlled by the lateral growth mechanism. The rate of lateral growth should be much smaller than the one of continuous growth at a given undercooling. The reason why the faceted interface advanced at a high velocity comparable to the curved interface one is that a curved surface which joins two facets each other (see Fig. 1b) can provide growth-steps for new layers on the facets.

3.2 FORMATION OF CRYSTAL DEFECTS IN Bi FILMS. - Crystal defects introduced during the melt growth or subsequent cooling process of the (111) films of Bi are short dislocations, dislocation loops, circular voids, lineage defects and triangular defects as shown in figure 2.

The short dislocations were formed just behind the growing interface. Their average density was of the order of $10^{10}-10^{11} \mathrm{~m}^{-2}$ and was higher in the low purity material, probably because dislocations would originate from chemical inhomogeneity in the impure crystal [29-31].

The nucleation of dislocation loops and circular voids were also detected just after melt growth and during successive cooling, although their contrast was poor. Their formation was remarkable in the presence of small temperature oscillation and in that case the sum of their densities amounted to the order of $10^{11} \mathrm{~m}^{-2}$. On the contrary, their formation was not observed in the $6 \mathrm{~N}$ 's films cooled without temperature oscillation, regardless of the cooling rate. Accordingly, it is considered that quenched-in vacancies necessary for the formation of these defects can be supplied under the presence of temperature oscillation.

Figures $3 a-d$ show the formation process of a lineage defect. It was usually nucleated at a small depression of the growing interface and then elongated into the grown part. Exceptionally, a short lineage defect was formed in the last solidified part of a liquid pool which was left behind the solid part. During subsequent cooling, long dislocations were occasionally emitted from some lineage defects. This indicates that the lineage defect is composed of a dislocation array which can act 


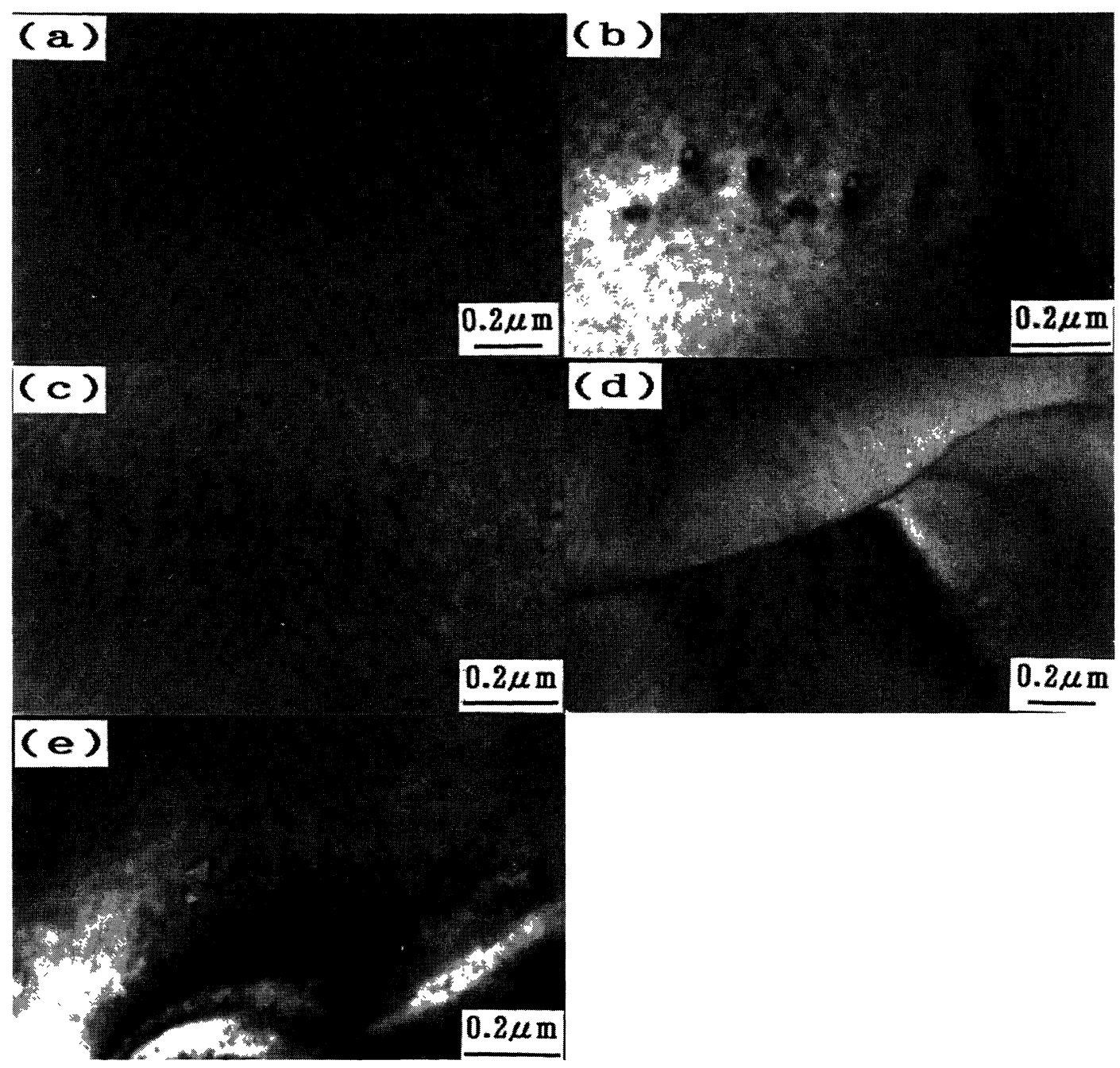

Fig. 2. - Crystal defects formed during the melt growth of (111) films of Bi (purity 6N's). a) Short dislocation, b) dislocation loops, c) circular voids, d) lineage defect and e) triangular defects.

as a dislocation source. The lineage defect formed was of the order of $10^{4}-10^{5} \mathrm{~m} / \mathrm{m}^{2}$ and was longer in the $3 \mathrm{~N}$ 's films than in the $6 \mathrm{~N}$ 's films. This suggests that the lineage defect also originates from chemical inhomogeneity introduced during melt growth [29-31]. As to the effects of small temperature oscillation and cooling rate on the lineage formation, we cannot obtain any definite conclusion.

The triangular defects were only formed during cooling by the use of the A-type controller. They appeared just after melt growth and grew in size during cooling. Their density was of the order of $10^{11} \mathrm{~m}^{-2}$. However, their origin is unknown.

3.3 GROWING INTERFACE AND CRYSTAL DEFECT IN Sn FILMS. - As shown in figure 4, the growing interface of Sn films was always concave toward melt, regardless of the film orientation and 


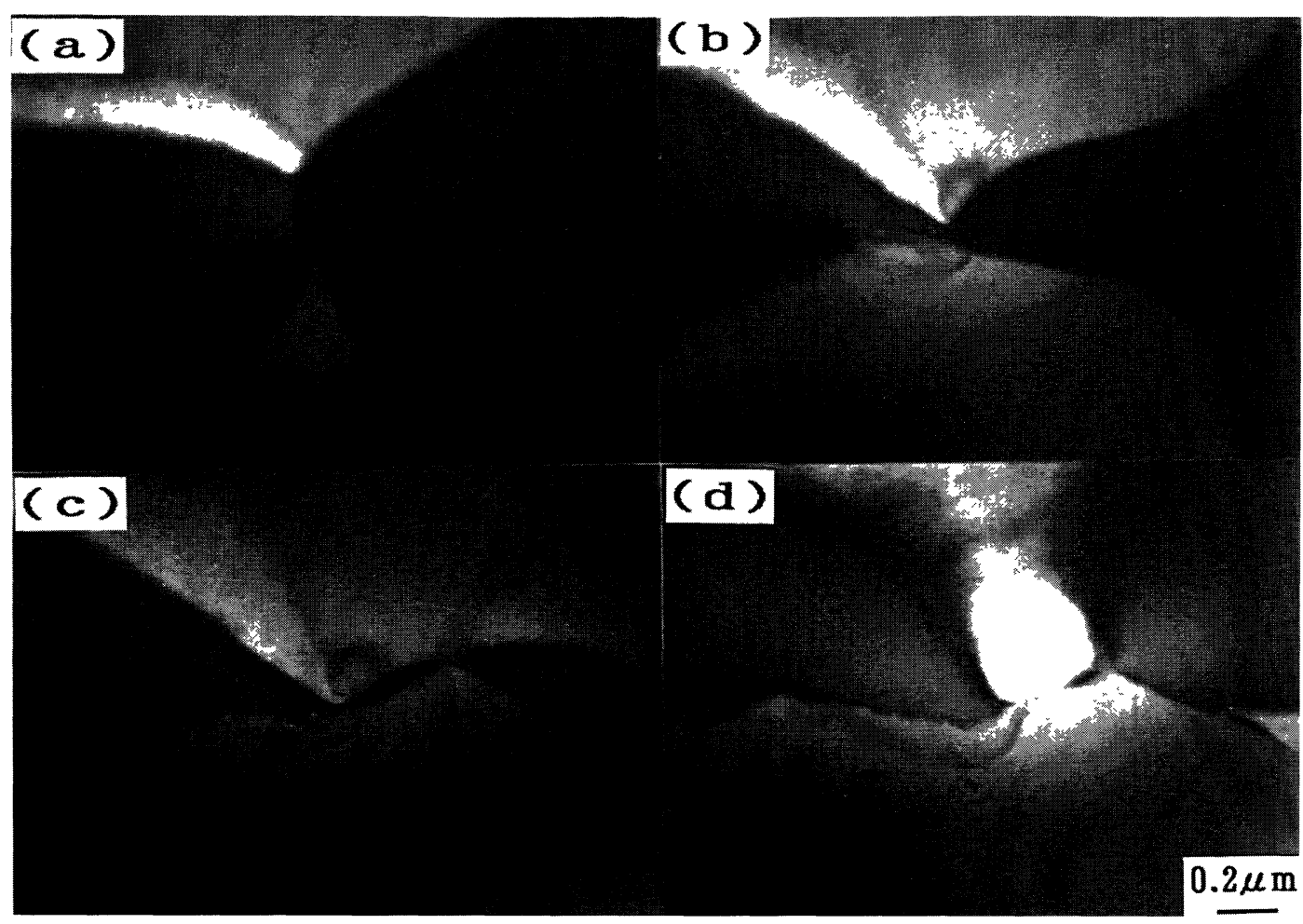

Fig. 3. - Formation of a lineage defect during the melt growth of a (111) film of Bi (purity $6 \mathrm{~N}$ 's) cooled at a rate of $8.3 \times 10^{-3} \mathrm{~K} / \mathrm{s}$. (a-c) During freezing and d) after freezed. The sides of a triangle inserted in $\mathrm{c}$ ) correspond to $\langle 1 \overline{1} 0\rangle$ directions.

the cooling rate. It is considered that the curvature would coincide with an isotherm as for the case of the curved interface of Bi films. Comparing figure $1 \mathrm{a}$ and figure 4, we find that the curved interface of $\mathrm{Sn}$ has smaller curvature than $\mathrm{Bi}$. This is because the thermal conductivity of $\mathrm{Sn}$ is about eight times as large as the one of $\mathrm{Bi}$. The occurrence of curved interface corresponds with prediction from the Jackson's criterion, since the value of $\alpha$ for $\mathrm{Sn}$ is 1.64. There was small difference between the average velocity of growing interface in the (100) film and in the (001) film one at each cooling rate. As the cooling rate was raised, their velocity first increased rapidly and then slowly.

During the melt growth of the (100) film, only the lineage defects were introduced. In most cases, the lineage defect was formed in the solid region near a depression part of solid-liquid interface (Fig. 5a), and then the defect was propagated into the newly grown films (Fig. 5b). Moreover, a lineage defect was infrequently generated in the last freezed part of a-liquid pool which was left behind an interface. The average length of lineage defects formed amounted to the order of $1-2 \times 10^{5} \mathrm{~m} / \mathrm{m}^{2}$ at any cooling rates. In the (001) films, however, no defects were observed.

\section{Summary.}

The information was obtained on the behavior of solid-liquid interface and crystal defects during the melt growth of $\mathrm{Bi}$ and $\mathrm{Sn}$ films from the in-situ observation by transmission electron mi- 


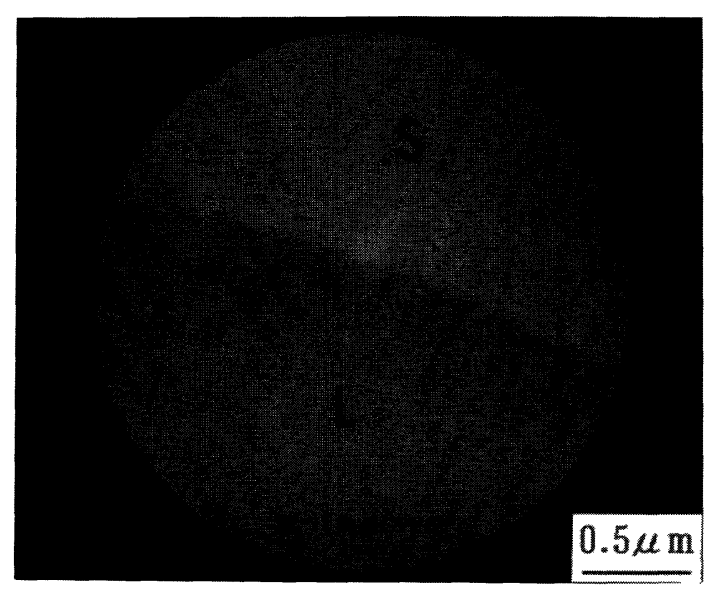

Fig. 4. - Video-recorded image showing the morphology of a growing interface of a (100) film of Sn (purity 5 N's).

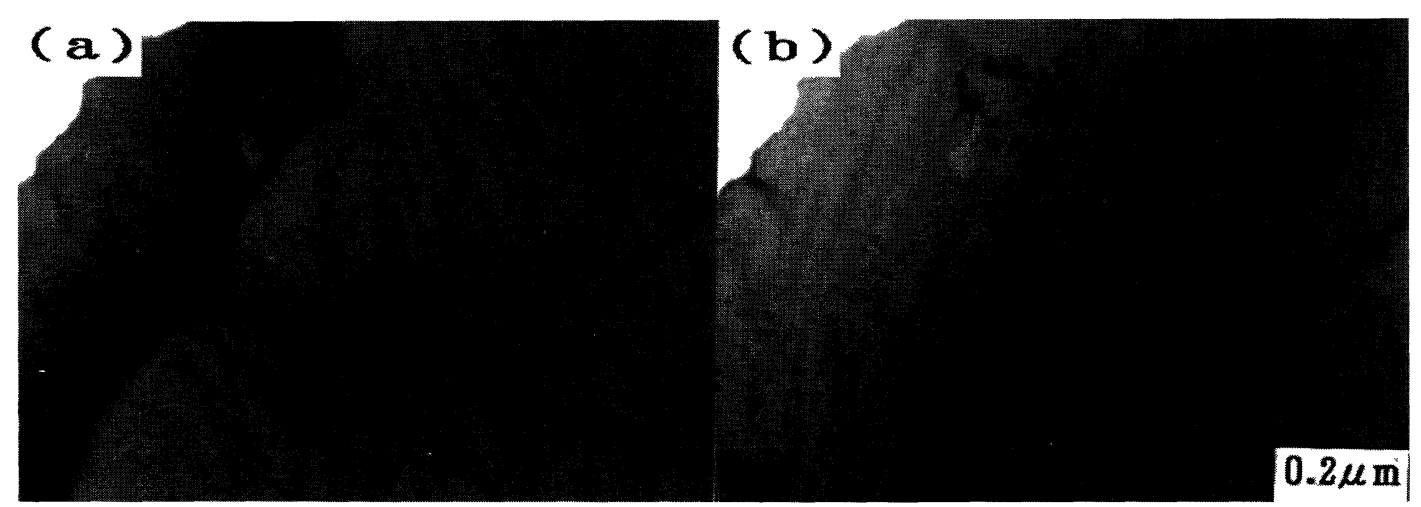

Fig. 5. - Formation of a lineage defect during the melt growth of a (100) film of Sn (purity 5N's) cooled at a rate of $8.3 \times 10^{-3} \mathrm{~K} / \mathrm{s}$. a) During freezing and $\mathrm{b}$ ) after freezed.

croscopy. In the (111) films of $\mathrm{Bi}$, the interface was concave toward the melt more frequently than faceted. The motion of curved interface reflected the external temperature change more sensitively than the faceted interface one. In the (100) and (001) films of Sn, the solid-liquid interface was always concave. Various crystal defects were formed during the melt growth of Bi films. Their density depended on the orientation and purity of films, and on the cooling conditions. On the contrary, only the lineage defects were introduced in the (100) films of Sn.

\section{Acknowledgements.}

We thank K. Takada for his help in the experiment. This work was partially supported by a Grantin-Aid for Scientific Research from the Ministry of Education, Science and Culture, Japan, No. 59580035 (1984). 


\section{References}

[1] GlickSMan M.E. and Vold C.L., Acta Met. 15 (1967) 1409.

[2] GLICKSMAN M.E. and VOLD C.L., J. Crystal Growth 13/14 (1972) 73.

[3] Chan Siu-Wai, LiU J.S. and BAllufFi R.W., Scripta Metall. 19 (1985) 1251.

[4] HSIEH T.E. and BALLUFFI R.W., Acta metall. 37 (1989) 1637.

[5] Glicksman M.E. and Vold C.L., Acta Met. 17 (1969) 1.

[6] Lemaignan C., CAMEl D. and PÉlissier J., J. Crystal Growth 52 (1981) 67.

[7] CAMEl D., Lesoult G. and Eustathopoulos N., J. Crystal Growth 53 (1981) 327.

[8] HAMAR R. and LEMAIGNAN C., J. Crystal Growth 53 (1981) 586.

[9] SaKa H., SasaKi A., Kamino T. and ImURa T., Phil. Mag. $\boldsymbol{A} 52$ (1985) L29.

[10] Fujita H., Tabata T., Yoshida K., Sumida N. and Katagiri S., J. Appl. Phys. Jpn. 11 (1972) 1522.

[11] COTTERILl R.M.J. and KRISTENSEN J.K., Phil. Mag. 36 (1977) 453.

[12] Lemaignan C., Acta Met. 29 (1981) 1379.

[13] SAKA H., NishiKaWA Y. and IMURA T., Phil. Mag. Lett. 55 (1987) 163.

[14] SAKA H., NishiKaWA Y. and IMURA T., Phil Mag. $\boldsymbol{A} 57$ (1988) 895.

[15] MOORE K.I., ZhANG D.L. and CANTOR B., Acta metall. mater. 38 (1990) 1327.

[16] SASAKI K. and SAKA H., Phil. Mag. A 63 (1991) 1207.

[17] FujtTA H., TABATA T. and AOKI T., J. Phys. Soc. Jpn. 42 (1977) 1429.

[18] Nittono O., Ogawa T., Gong S.K. and Nagakura S., J. Appl. Phys. Jpn. 23 (1984) L581.

[19] KobaYASHI T. and IMURA T., J. Appl. Phys. Jpn. 23 (1984) L632.

[20] GRANGE G., Jourdan C., Coulet A.L. and GASTALDI J., J. Crystal Growth 72 (1985) 748.

[21] Grange G., Gastaldi J. and Jourdan C., J. Appl. Phys. 62 (1987) 1202.

[22] KoBAYASHI T., NiSHIKAWA Y. and IMURA T., J. Crystal Growth 84 (1987) 489.

[23] Watanabé J., Sugawara S. and Funato A., Trans. Jpn. Inst. Metals 27 (1986) 939.

[24] TOKORO T., SugaWARA S. and WatanabÉ J., Mater. Trans. JIM 31 (1990) 759.

[25] Yамамото M., Sci. Rep. Tohoku Univ. 31 (1943) 121.

[26] JACKSON K.A., Growth and Perfection of Crystals, Eds. R.H. Doremus, B.W. Robert and D. Turnbull (Wiley, London, 1958) p. 319.

[27] WoodRUFF D.P., The Solid-Liquid Interface (Cambridge Univ. Press, London, 1973) p. 47.

[28] JACKSON K.A., Crystal Growth and Characterization, Eds. R. Ueda and J.B. Mullin (North-Holland Pub., Amsterdam, 1975) p. 21.

[29] Tiller W.A., J. Appl. Phys. 29 (1958) 611.

[30] FRIEDEL J., Dislocations (Pergamon Press, Oxford, 1964) p. 206.

[31] JAFFrey D. and ChaDwiCK G.A., Phil. Mag. 18 (1968) 573. 